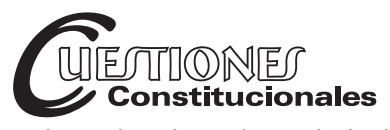

Revista Mexicana de Derecho Constitucional Núm. 39, julio-diciembre 2018

\title{
El principio pro persona: la fórmula del mejor derecho
}

\author{
The Pro Persona Principle: the Formula \\ of the Best Right
}

\section{Gerardo Mata Quintero*}

Resumen: en este trabajo se parte de considerar al principio pro persona como una cláusula constitucional preferente que, sin embargo, no ha sido tomada lo suficientemente en serio por la jurisprudencia constitucional ni por la doctrina, pues no se trata de una invocación de lo más favorable, benéfico o maximizador, como si fuere algo evidente o intuitivo $\mathrm{y}$, por tanto, carente de cualquier valoración. Desde una visión garantista del derecho, tomarse en serio el principio pro persona implica realizar un ejercicio argumentativo que responda a las preguntas: favorable, ¿para quién?, o, ¿cómo se determina si tal o cual disposición normativa o interpretación es la que favorece a la persona? Así, se propone un entendimiento estructural del principio pro persona que comprende sus sentidos, directrices, dimensiones, elementos, criterios y objetos, en torno a su significado: favorecer la protección de las personas.

Palabras clave: principio pro persona, fórmula del mejor derecho, favorecer la protección, derechos humanos.
ABSTRACT: in this paper it is considered that the pro persona principle is a preferential constitutional clause that hasn't been analyzed sufficiently by the constitutional jurisprudence nor by the juridical doctrine because it has been understood merely as an invocation of the most favorable, beneficial or maximizer solution, as something evident and intuitive, and thereof lacking any kind of valuation. From a garantista vision of the law, taking the pro persona principle seriously implicates argumentative exercises that answer these questions: favorable, to whom? Or, how do we know that the certain norm or interpretation is the one that favors the person? Therefore a structural understanding of the pro persona principle is based in its directions, directives, dimensions, elements, criterial and objects, around its meaning:to favor the protection of the persons.

Keywords: Estructure of pro Persona Principle, Formula of the Best Right, Favor the Protection, Human Rights.

* Maestro en derecho por la Universidad Autónoma de Coahuila. Doctorando en derecho, gobierno y políticas públicas por la Universidad Autónoma de Madrid. gerardo. mata@predoc.uam.es. 
SUMARIO: I. El principio pro persona como ley más favorable y el problema de la arbitrariedad judicial. II. Una construcción estructural del principio pro persona. III. Un esquema de la "fórmula del mejor derecho". IV. Apuntes finales. V. Bibliografía.

\section{EL PRINCIPIO PRO PERSONA COMO LEY MÁS FAVORABLE Y EL PROBLEMA DE LA ARBITRARIEDAD JUDICIAL}

La asunción del paradigma constitucional ha significado un cambio importante en cómo se concibe la Constitución en el Estado, y las formas en que se desarrollan las prácticas judiciales modernas y en que se explican las disciplinas jurídicas ${ }^{1}$. Con aquél se pasó de un Estado legislativo de derecho a un Estado constitucional, ${ }^{2}$ lo cual no es una mera cuestión terminológica, sino que tiene profundas implicaciones formales y, sobre todo, sustanciales en el entendimiento que hasta ahora se ha tenido de la Constitución misma, la democracia, los derechos fundamentales - como objetos de estudio de la ciencia jurídica-, pero también de su relación con quienes los interpretan, es decir, quienes operan en el derecho - especialmente el Poder Legislativo, en la semántica de la legislación, y el Poder Judicial, a nivel pragmático-.

En el constitucionalismo, entonces, se reposiciona "el valor de la Constitución como conjunto de normas sustanciales" que impone vínculos expresados a través de los principios y derechos fundamentales en ella contenidos. ${ }^{3}$ Así, los principios y los derechos fundamentales establecidos en la Constitución ${ }^{4}$ se convierten en el parámetro de validez —y, más aún, de

1 Ferrajoli, Luigi, Derechos y garantías. La ley del más débil, trad. de Perfecto Andrés Ibáñez y Andrea Greppi, Madrid, Trotta, 1999, p. 68; Carbonell, Miguel, "El neoconstitucionalismo: significado y niveles de análisis", en Carbonell, Miguel y García Jaramillo, Leonardo (eds.), El canon neoconstitucional, Madrid, Trotta, 2010, pp. 154158.

2 Ferrajoli, Luigi, "Pasado y futuro del Estado de derecho", en Carbonell, Miguel (ed.), Neoconstitucionalismo(s), trad. de P. Allegue, Madrid, Trotta, 2009, p. 14; Zagrebelskey, Gustavo, El derecho dúctil. Ley, derechos, justicia, trad. de Marina Gascón, Madrid, Trotta, 2011, p. 33.

3 Ferrajoli, Luigi, Derechos y garantías..., cit., pp. 65-68.

4 No se debe olvidar la recepción jurisprudencial en nuestro sistema constitucional de los planteamientos relativos a la existencia de un "bloque de constitucionalidad" o 
invalidez - de todas las demás normas del ordenamiento jurídico regido por la Constitución, determinando tanto las formas de producción - que redundarán en la vigencia de las normas inferiores-, como también la coherencia entre sus contenidos.

Así, la positivación de los derechos fundamentales en la Constitución tiene como una de sus consecuencias, en el plano jurisdiccional, la "reinterpretación del sistema normativo en su totalidad a la luz de los principios" constitucionales, ${ }^{5}$ en razón de que la Constitución deja de ser un mero documento político-ideológico que simplemente expresa buenas intenciones o que "no es más [que] una declaración de buenos deseos [o] un compendio de normas programáticas", ${ }^{6}$ sino que ahora la Constitución es además, y sobre todo, una norma jurídica suprema, ${ }^{7}$ en sentido fuerte, ${ }^{8}$ que "se concibe como un sistema de garantías, esto es, de límites y vínculos jurídicos impuestos al ejercicio de cualquier poder como condición de su legitimidad". 9

\footnotetext{
"bloque de regularidad normativa" que la Suprema Corte de Justicia de la Nación (SCJN) ha aceptado: tesis P. LXVIII/2011, de rubro "PARÁMETRo PARA EL CONTROL DE CONVENCiONALIDAD EX OFFICIO EN MATERIA DE DEReChos humanos", Semanario Judicial de la Federación y su Gaceta, Décima Época, t. 1, diciembre de 2011, p. 551, registro IUS: 160526. Tesis P./J. 20/2014, de rubro "Derechos humanos ConTENidos EN LA ConstiTUCIÓN Y EN LOS TRATADOS INTERNACIONALES. Constituyen el parámetro de control de regularidad constitucional, pero cuando en la Constitución haya una restricción expresa al ejercicio de aquéllos, se debe estar a lo que establece el texto constitucional", Semanario Judicial de la Federación y su Gaceta, Décima Época, t. I, abril de 2014, p. 202, registro IUS: 2006224. En tal sentido Caballero Ochoa, José Luis, "La cláusula de interpretación conforme y el principio pro persona (artículo primero, segundo párrafo, de la Constitución)", en Carbonell, Miguel y Salazar Ugarte, Pedro (coords.), La reforma constitucional de derechos humanos: un nuevo paradigma, México, Porrúa-UNAM, Instituto de Investigaciones Jurídicas, 2012, pp. 115, 116, 121 y 122.

5 Ferrajoli, Luigi, Derechos y garantías..., cit., p. 68.

6 Ortega García, Ramón, El modelo constitucional de derechos humanos en México. Estudios sobre constitucionalización del derecho, México, Tirant lo Blanch, 2015, p. 28.

7 Fioravanti, Maurizio, Los derechos fundamentales. Apuntes de historia de las Constituciones, trad. de M. Martínez Neira, Madrid, Trotta, 1996, p. 128.

8 Prieto Sanchís, Luis, "Supremacía, rigidez y garantía de la Constitución”, en Bernal Pulido, Carlos y Herber, Joel (eds.), Control constitucional y activismo judicial, Perú, Ara Editores, 2012, p. 266.

9 Ferrajoli, Luigi, La democracia a través de los derechos. El constitucionalismo garantista como modelo teórico y como proyecto político, trad. de Perfecto A. Ibáñez, Madrid, Trotta, 2014, p. 23.
} 
Pero esta reconfiguración del Estado, de la naturaleza de la legalidad positiva, impacta no solamente al orden constitucional, a nivel dogmático, sino también los discursos que sobre él se desarrollan, tanto en la jurisdicción como en la ciencia jurídica. A su vez, las teorías de los derechos posteriores a la Segunda Guerra Mundial han estipulado una especie de carácter preferente de los derechos dentro del constitucionalismo - según se entienda este último - frente a otras normas o categorías normativas, al establecer que estos derechos actúan en cuanto "triunfos", 10 "mandatos de optimización" 11 o normas que forman la "esfera de lo indecidible". ${ }^{12}$

Este estatus de preferencia normativa de los derechos fundamentales dentro de la estructura constitucional se expresa, a nivel dogmático, de diferentes maneras. Una de ellas es la de su aplicación e interpretación. En particular, la interpretación de las normas que estipulan este tipo de derechos se hace de manera que se pueda lograr la efectividad de los derechos mismos, a partir de lo cual se diseñan criterios hermenéuticos propios. ${ }^{13}$

Uno de ellos es el principio pro persona, el cual tiene una naturaleza doble: por un lado, es un "criterio hermenéutico que informa todo el derecho de los derechos humanos", ${ }^{14}$ orientando tanto la aplicación como la interpretación de la disposición normativa que sea más favorable a la persona y a sus derechos. Por otra parte, este principio tiene como vocación resolver controversias metainterpretativas, que no se refieren ya a las diferentes interpretaciones de una misma disposición normativa, sino propiamente al método de interpretación que debe emplearse. ${ }^{15}$

10 Dworkin, Ronald, Los derechos en serio, trad. de M. Guastavino, España, Ariel, 1977, pp. 37 y 495.

11 Alexy, Robert, Teoría de los derechos fundamentales, trad. de Carlos Bernal Pulido, Madrid, Centro de Estudios Políticos y Constitucionales,1986, p. 68.

12 Ferrajoli, Luigi, Derecho y razón. Teoría del garantismo penal, trad. de Perfecto Andrés Ibáñez et al, Madrid, Trotta, 1995, pp. 864 y ss.

13 Nash Rojas, Claudio, "El principio pro persona en la jurisprudencia de la Corte Interamericana de Derechos Humanos”, en Nogueira Alcalá, Humberto (coord.), Diálogo judicial multinivel y principios interpretativos favor persona y de proporcionalidad, Santiago de Chile, Librotecnia-Centro de Estudios Constitucionales de Chile, 2013, pp. 157 y 168 .

14 Pinto, Mónica, "El principio pro homine. Criterios de hermenéutica y pautas para la regulación de los derechos humanos", en Abregú, M. y Courtis, Christian (comps.), La aplicación de los tratados sobre derechos humanos por los tribunales locales, Buenos Aires, Editores del Puerto, 1997, p. 163.

15 Guastini, Riccardo, "Para una taxonomía de las controversias entre juristas", en 
Este principio, en sus inicios denominado principio pro homine, ha tenido su mayor difusión y desarrollo principalmente en el derecho internacional de los derechos humanos, ${ }^{16}$ pero también se ha ido incorporando a los sistemas jurídicos nacionales, como ha sido el caso mexicano a través de la reforma al artículo 1o., entre otros, de la Constitución Política de los Estados Unidos Mexicanos (CPEUM), publicada el 10 de junio de 2011 en el Diario Oficial de la Federación. ${ }^{17}$

Desde su inclusión en la disposición constitucional, el principio ha sido abordado por la jurisprudencia en términos de "favorecer", "beneficiar", "maximizar", ${ }^{18}$ pero no se ha logrado explicar, ni mucho menos sistemati-

Luque Sánchez, Pau y Ratti, Giovanni Battista (eds.), Acordes y desacuerdos. Cómo y por qué los juristas discrepan, Madrid, 2012.

16 Castilla, Karlos, "El principio pro persona en la administración de justicia", Cuestiones Constitucionales, México, núm. 20, enero-junio de 2009, p. 70. Por su parte, ya desde 1981 la Corte Interamericana de Derechos Humanos (CoIDH) sostiene el mandato de interpretación más favorable: CoIDH, asunto Viviana Gallardo y otras, decisión del 13 de noviembre de $1981, \S 16$.

17 No debe olvidarse, sin embargo, que tal como lo ha interpretado la CoIDH, del artículo 29 de la Convención Americana sobre Derechos Humanos (CADH) deriva el mandato de "mayor favorabilidad": CoIDH, La colegiación obligatoria de periodistas (artículos 13 y 29 Convención Americana sobre Derechos Humanos), OC-5/85 de 13 de noviembre de 1985, serie A, núm. 5, §52; más recientemente: CoIDH, caso Trabajadores de la Hacienda Brasil verde vs. Brasil, sentencia de excepciones preliminares, fondo, reparaciones y costas de 20 de octubre de 2016, serie C, núm. 318, §§311-312. Por tanto, y al haber ratificado el Estado mexicano la CADH en 1981, tratado internacional que desde entonces forma parte de la "Ley Suprema de toda la Unión", en términos del artículo 133 constitucional, se puede válidamente sostener que este principio cuenta con una historia - aunque olvidada o inatendida - de casi 40 años en nuestro sistema constitucional.

18 Véase de la SCJN tesis 1a./J. 37/2017, de rubro "INTERPRETACión CONFORME. Naturaleza y alcances a la luz del principio pro persona", Semanario Judicial de la Federación y su Gaceta, Décima Época, t. I, mayo de 2017, p. 239, registro IUS: 2014332. Tesis P./J. 21/2014, de rubro "JuRISPRUdEnCIA EMITIDA POR LA CORTE INTERAMERICANA De Derechos Humanos. Es vinculante para los jueces mexicanos siempre que sea más favorable a la persona", Semanario Judicial de la Federación y su Gaceta, Décima Época, t. I, abril de 2014, p. 204, registro IUS: 2006225. Tesis 1a. CCCLI/2014, de rubro: "PrinCIPIOS DE INTERPRETACIÓn CONFORME Y PRO PERSONA. Son aplicables a los juicios civiles", Semanario Judicial de la Federación y su Gaceta, Décima Época, t. I, octubre de 2014, p. 615, registro IUS: 2007735. Tesis 1a. CCCXXVII/2014, de rubro "PrINCIPIO PRO PERSONA. Requisitos mínimos para que se atienda el fondo de la solicitud de su aplicación, o la impugnación de su omisión por la autoridad responsable", Semanario Judicial de la Federación y su Gaceta, Décima Época, t. I, octubre de 2014, p. 613, registro IUS: 2007561. 
zar, qué significan estos criterios ni se han establecido los parámetros para testear las opciones disponibles en los casos concretos, ni mucho menos se ha dejado en claro a quiénes se debe favorecer o beneficiar, sobre todo cuando ello implique desfavorecer o minimizar otros derechos o los derechos de otros sujetos. Así, pareciere ser que el proceso de concreción frente a estas preguntas es algo más intuitivo o incluso evidente, que no necesita, por tanto, de guías o lineamientos que orienten a los órganos juzgadores y a las demás autoridades a cumplir cabalmente con su obligación constitucional y convencional de "favorecer en todo tiempo la protección más amplia".

Del estado de cosas en torno al nulo esfuerzo por la jurisprudencia o la doctrina de desarrollar en serio el mandato de esta cláusula constitucional preferente como una herramienta jurídica para garantizar y potencializar la protección de los derechos de las personas, se abre paso a dos problemas puntuales.

El primero, más general y no exclusivo del campo de aplicación del principio pro persona, surge en el sentido de que, al no contarse con parámetros que en alguna medida contribuyan a identificar las opciones normativas o interpretativas disponibles que sean más favorables, o bien que indiquen favorables para quién, pareciere ser que o tales parámetros no son necesarios, porque la respuesta siempre es evidente, o simplemente no es posible o no se quiere construirlos; todo esto abona a la cuestión de la discrecionalidad judicial — la cual es "fisiológica" en los sistemas jurídicos dogmáticos que admiten "espacios de la interpretación judicial", ${ }^{19}$ y por tanto irreducible más allá de cierta medida, pero reducible a través de reglas y de garantías $-{ }^{20}$ y que, si no es controlada, puede fácilmente degenerar en arbitrariedad judicial.

El segundo problema, más específico y propio de este principio, pero que es alimentado por el primero, es justamente que se trata de un mandato sustancial, una de las promesas más importantes que hace nuestra Constitución de que somos las personas quienes ocuparemos en todo momento el lugar central y protagónico del derecho y que, sin embargo, al no ser desarrollado en sus alcances, se corre el peligro de que el principio pro persona

19 Ferrajoli, Luigi, "Constitucionalismo principialista y constitucionalismo garantista, un debate sobre el constitucionalismo monográfico", Doxa, núm. 34, trad. de N. Guzmán, Madrid, Marcial Pons-Doxa, 2012, p. 42.

20 Ferrajoli, Luigi, Derecho y razón. Teoría..., cit., p. 62. 
no sea más que un "criterio endeble, absolutamente subjetivo, construido de buenas intenciones y modulado en el sentido que se prefiera", ${ }^{21}$ y con ello no sea más que un capricho para legitimar decisiones públicas - especialmente judiciales - invocando una mera fórmula vacía cuyo misterio hace que sea imposible develar $\mathrm{y}$, por tanto, evaluar.

Esto puede palparse fácilmente, siguiendo a Bobbio cuando señala uno de los problemas más importantes al cual se enfrenta quien interpreta las normas buscando la lex favorabili; no es tanto lograr la preferencia de esa norma sobre alguna otra — que ya es un mandato constitucional-, sino el de "establecer a cuál de los dos sujetos de la relación jurídica es más justo proteger, esto es, cuál de los dos intereses en conflicto es justo hacer prevalecer", ${ }^{22}$ para lo cual el mandato de la "ley más favorable", al menos abordado como hasta ahora, no ofrece la más mínima ayuda.

De ello se hace notar la necesidad de estudiar y analizar seriamente las implicaciones y exigencias de este mandato constitucional y convencional del cual son destinatarias todas las autoridades públicas del país, particularmente las judiciales, que ordena favorecer siempre a las personas y a sus derechos, pero que ni aún en sede interpretativa se ha logrado descifrar qué es, al menos en términos generales, lo que ese mandato implica o bien cómo es que se cumple, puesto que lo único que se ha hecho hasta ahora es repetir la fórmula de lo "más favorable", sin dar mayor pauta para su desarrollo.

La idea de este trabajo es, entonces, aportar al desarrollo de la fórmula del "mayor beneficio" en materia de derechos fundamentales, de manera que se tenga mejor claridad a la hora de buscar esas opciones que favorezcan, beneficien o maximicen derechos, haciéndose cargo de una de las que hoy son las preocupaciones centrales de la teoría constitucional: el problema de la interpretación. Ello para buscar "esquemas interpretativos que maximicen la 'capacidad prestacional' — es decir, la posibilidad de

21 Caballero Ochoa, José Luis y García Huerta, Daniel Antonio, "El principio pro persona en el marco del sistema de interpretación sobre los derechos humanos en México", en Ferrer Mac-Gregor, Eduardo (coord.), Derecho procesal constitucional transnacional. Interacción entre el derecho nacional y el internacional, México, Porrúa-Instituto Mexicano de Derecho Procesal Constitucional, 2016.

22 Bobbio, Norberto, Teoría general del derecho, trad. de J. Guerrero, Bogotá, Temis, 2012, p. 201. 
tener efectos prácticos sobre la realidad cotidiana-" ${ }^{\prime 23}$ del mandato constitucional que encierra al principio pro persona.

Se pretende lograr este objetivo, desde una posición garantista y crítica del derecho, a través del desengrane del principio pro persona a partir de su formulación constitucional, de forma que se pueda entender su estructura compleja y ello ayude a identificar sus implicaciones y los referentes para su concreción en un caso determinado, en torno a su significado como herramienta para favorecer a las personas y sus derechos.

En esta búsqueda de mayor certeza y control en la actividad decisional, sin embargo, no es posible desconocer que nos encontramos dentro del campo del poder de disposición judicial. Este poder, conformado por los de denotación de las normas, verificación probatoria y connotación de los hechos, aunque puede ser disciplinado en mayor o menor medida, es fisiológico a la actividad judicial, y por ello insuprimible. ${ }^{24} \mathrm{Y}$, en particular, el poder de connotación de los hechos, al ser presidido por la equidad como regla semántica del juicio, requiere, inevitablemente, de juicios de valor, los cuales son subjetivos, no verificables ni refutables, en términos de verdad. Debido a esta subjetividad, los criterios de valoración que presiden la connotación y la comprensión equitativa son innumerables y variados ya que, debido a su naturaleza, escapan a una completa predeterminación. De ahí que sería en vano pretender criterios ciertos y objetivos de un principio, como el pro persona, que tiene su aplicación, en gran medida, en el poder de connotación judicial ${ }^{25}$ y que precisa de una actitud empática para la comprensión de los hechos.

No está de más aclarar que, con lo anterior, lo único que se está diciendo es que fisiológicamente es imposible predeterminar los criterios concretos que permitan, inequívocamente en todos los casos, indicar cuál es la interpretación o la norma que será la que favorezca a las personas o hasta dónde es legítimo hacerlo. Se puede decir, por ende, que las exigencias del principio pro persona tienen una vocación de satisfacción en los casos concretos que tengan que ser denotados por las normas, verificados probatoriamente, connotados en sus particularidades y argumentados jurídicamente. Entonces, lo que sí se puede hacer es intentar construir los puntos

23 Carbonell, Miguel, Los derechos fundamentales en México, México, CNDHUNAM, 2004, p. 127.

24 Ferrajoli, Luigi, Derecho y razón. Teoría..., cit., pp. 38, 40 y 117.

25 Ibidem, p. 405. 
de referencia que permitan concretar en cada caso el mandato constitucional de favorabilidad a partir de las exigencias e implicaciones derivadas de la estructura del principio pro persona.

Así las cosas, este trabajo se desarrollará en tres apartados más. El siguiente retomará la construcción que la doctrina ha hecho del significado del principio pro persona para, a partir de una lectura de su formulación constitucional, proponer una construcción estructural de este principio que permita visualizar sus alcances; luego, se pasará a proponer un esquema estructurado de cuestionamientos que provean líneas de respuestas para adoptar una solución jurídica en casos concretos en que entre en juego el principio; finalmente, se examinarán un par de casos poniendo en operación el esquema propuesto y se ofrecerán algunas conclusiones que buscan aligerar los problemas anteriormente señalados.

\section{UNA CONSTRUCCIÓN ESTRUCTURAL DEL PRINCIPIO PRO PERSONA}

Primeramente, se debe enfatizar que el mandato constitucional que encierra la esencia del principio pro persona configura una cláusula constitucional preferente, en razón de que se trata de una expresión positiva directa del fundamento axiológico, desde el punto de vista externo, ${ }^{26}$ tanto del derecho como del Estado: la tutela de las personas y de sus derechos fundamentales. ${ }^{27}$

Se puede decir que es preferente, en función de su relación directa con el valor de las personas y de su capacidad de vinculación con la técnica idónea para su protección, que son los derechos fundamentales; esto a diferencia de otras cláusulas constitucionales como lo podría ser, por ejemplo, el principio de federalismo, puesto que aun cuando tenga rango constitucional, a lo sumo tiene una relación indirecta con las personas y sus derechos, pues más que buscar su protección, pretende organizar la distribución de competencias del poder público en diferentes niveles. Dada su constitución como cláusula constitucional preferente significa que va más allá de una mera "recomendación, puramente negativa, de no practicar la

26 Sobre los puntos de vista interno y externo Winch, Peter, The Idea of a Social Science and its Relation to Philosophy, 2a. ed., 1990, Londres, Routledge, 1958; en el campo del derecho, Hart, Herbert L. A., El concepto de derecho, México, Nacional, 1980.

27 Ferrajoli, Luigi, La democracia a través..., cit., p. 83; id., Derecho y razón. Teoría..., cit., pp. 905 y ss. 
interpretación restrictiva". ${ }^{28}$ En todo caso, se corresponde con un mandato de favorecimiento, con fuerza normativa propia, y que no solamente incluye a las interpretaciones, sino también a la aplicación de las normas.

El planteamiento más difundido del principio pro persona elaborado por la doctrina es comúnmente formulado en el sentido de que se trata de un mandato según el cual "se debe acudir a la norma más amplia, o a la interpretación más extensiva, cuando se trata de reconocer derechos protegidos e, inversamente, a la norma o a la interpretación más restringida cuando se trata de establecer restricciones permanentes al ejercicio de los derechos o su suspensión extraordinaria". ${ }^{29}$ A partir de lo anterior es posible hacer una primera distinción en la estructura de este principio dependiendo del punto que sea enfatizado: primero, el sentido en que sea aplicado, y segundo la dirección de la preferencia en que se aplique.

En primer término, se puede decir que son dos los sentidos en los que se puede hablar del principio pro persona: uno positivo y el otro negativo. El primero se identifica con la exigencia de acudir a la formulación normativa o a la interpretación más amplia, siempre que se trate de reconocer, promover, respetar y garantizar los derechos protegidos. En cambio, el principio pro persona, en sentido negativo, implica que se debe preferir la disposición normativa o la interpretación más restringida cuando se trata de establecer restricciones al ejercicio de los derechos y las libertades reconocidas.

Visto desde otra perspectiva, el principio pro persona cuenta con dos "directrices de preferencia": ${ }^{30}$ la primera es la interpretación más favorable, mientras que la segunda se dirige hacia la aplicación de las

28 Guastini, Riccardo, Interpretar y argumentar, trad. de Silvina Álvarez Medina, Madrid, Centro de Estudios Políticos y Constitucionales, 2014, p. 378. Cursivas del original.

29 Pinto, Mónica, “El principio pro homine...”, cit., p. 163; Castilla, Karlos, “El principio pro persona en...", cit., pp. 69 y 70; Medellín Urquiaga, Ximena, "Principio pro persona", Metodología para la enseñanza de la reforma constitucional en materia de derechos humanos, México, Suprema Corte de Justicia de la Nación, Oficina en México del Alto Comisionado de las Naciones Unidas para los Derechos Humanos-Comisión de Derechos Humanos del Distrito Federal, 2013, pp. 19 y 27.

30 Sagüés, Néstor Pedro, "La interpretación de los derechos humanos en las jurisdicciones nacional e internacional", Anales de la Academia Nacional de Derecho y Ciencias Sociales de Buenos Aires, Segunda Época, año XLIII, núm. 36, 1998, pp. 136-138; Medellín Urquiaga, Ximena, "Principio pro persona", cit., p. 27. 
normas que más favorezcan. ${ }^{31}$ Interpretación, por un lado; aplicación, por otro. La preferencia interpretativa se despliega cuando existan dos o más interpretaciones jurídicamente válidas —una vez aplicados los distintos métodos de interpretación jurídica como el literal, contextual, teleológico, sistemático, etcétera-, para preferir aquella que favorezca la protección de los derechos, sea en sentido positivo o negativo; por otra parte, la preferencia normativa se da cuando existan dos o más normas jurídicas aplicables a un mismo punto de derecho pero que son incompatibles en sus significados, de forma que se debe preferir aplicar la norma que favorezca la protección constitucional.

Luego, de una lectura detenida del artículo 1o., párrafo 2, de la CPEUM, es posible extraer otros datos que permiten hacer un bosquejo más acabado de este principio, que si bien su denominación no aparece expresamente en el texto, sí quedó en él concretado el mandato que "sintetiza, al final de cuentas, la esencia del principio pro persona... Las normas relativas a los derechos humanos se interpretarán de conformidad con esta Constitución y con los tratados internacionales de la materia favoreciendo en todo tiempo a las personas la protección más amplia" 32 (énfasis añadido).

De esta formulación constitucional el principio puede ser diseccionado en tres elementos básicos que forman parte de su estructura:

1. Un elemento de temporalidad: que se configura "en todo tiempo";

2. Un elemento personal: cuando se dirige "a las personas"; $y$,

3. Un elemento material: que se da en relación con "la protección más amplia".

Estas primeras consideraciones sobre sus componentes estructurales permiten acercarnos un poco más a la concreción de la "fórmula del mejor derecho": ${ }^{33}$ se debe preferir la disposición normativa o la interpretación jurídica que favorezca, durante el mayor tiempo posible y a un mayor rango de personas, las formas de protección más óptimas.

31 Piza Rocafort, Rodolfo y Trejos, Gerardo, Derecho internacional de los derechos humanos: la Convención Americana, San José, Juricentro, 1989, p. 67; López Sánchez, Rogelio, Interpretación constitucional de los derechos fundamentales. Nuevos paradigmas hermenéuticos y argumentativos, México, Porrúa, 2013, pp. 34 у 35.

32 Medellín Urquiaga, Ximena, "Principio pro persona...", cit., p. 8.

33 Sagüés, Néstor Pedro, "La interpretación de los...", cit., p. 158. 
En cualquier caso, el favorecimiento al que se refiere el mandato constitucional en cuestión, sea en sentido positivo o negativo, tendría que darse con respecto a los tres elementos referidos, pues sería contrario a su propia esencia pretender aislarlos, para buscar la satisfacción individual de solamente uno de ellos, en perjuicio de los otros. Esto es: no sería válido argumentar, por ejemplo, una protección más amplia, pero que tuviere como efecto o consecuencia, que fuere para un número menor de personas o por un periodo de tutela más reducido.

Lo anterior es así en razón de una especie de relación de "indivisibilidad" e "interdependencia" entre los elementos que constituyen el mandato de favorecimiento, como sucede con los derechos humanos. Y dado que no es válido aislarlos, el cumplimiento del principio pro persona exige que sus tres componentes sean considerados al momento de determinar la solución que favorezca a la persona y a sus derechos. Sin embargo, esta idea de interdependencia entre elementos no significa que con la solución jurídica - normativa o interpretativa- que se adopte en el caso concreto, los tres deban expandirse, cada uno de ellos, en sentido positivo o negativo, en una medida equivalente, para considerar que se está cumpliendo con el mandato pro persona, pues si bien son dependientes entre sí, debe reconocérseles un ámbito propio que permita diferenciarles uno de otros.

Siguiendo la línea trazada, entonces el principio pro persona se corresponde con un mandato de preferencia, entre varias interpretaciones jurídicas de una misma norma, o entre distintas normas aplicables a una misma situación, de aquella interpretación de la norma, en el primer caso, o de aquella norma, en el segundo, favoreciéndose así la mayor ${ }^{34}$ y la mejor ${ }^{35}$ protección de las personas y sus derechos. Por tanto, la protección sustentada por el principio pro persona puede verse a través de su dimensión cuantitativa - la mayor-, así como de la cualitativa - la mejor-.

Como visto antes, lo único que las directrices de preferencia del principio pro persona nos dicen es que debe escogerse una cierta interpretación de una norma, o bien una cierta norma - aquellas que favorezcan a las personas - . Pero serán las dimensiones cuantitativa y cualitativa de este

34 Sepúlveda Iguíniz, Ricardo, "El reconocimiento de los derechos humanos y la supremacía de la Constitución”, en Rosario Rodríguez, Marcos del (ed.), Supremacía constitucional, México, Porrúa-Universidad Panamericana, 2009, p. 210.

35 Henderson, Humberto, "Los tratados internacionales de derechos humanos en el orden interno: la importancia del principio pro homine", Revista del Instituto Interamericano de Derechos Humanos, México, núm. 39, enero-junio de 2004, p. 87. 
principio las que determinan, en función de la mayor y la mejor protección que ofrezcan, esa interpretación de la disposición normativa (dentro de las jurídicamente válidas) o esa norma (dentro de las jurídicamente aplicables) la que deba ser preferida.

Luego, es posible identificar que la relación existente entre las dos dimensiones del principio pro persona y los elementos que lo constituyen, se da en el sentido de que los dos primeros de los elementos identificados - el de temporalidad y el personal- conforman la dimensión cuantitativa, mientras que el tercero - el elemento material— es el núcleo de la dimensión cualitativa del principio mismo. Así las cosas, aumentando la base cuantitativa de tiempo y de sujetos tutelados, se favorece la mayor protección, mientras que verificar la cualidad material de las modalidades de garantía, favorece la mejor protección.

Ahora bien, es necesario, para no quedar en meras formulaciones abstractas y vagas, determinar qué se entiende por "favorecer la protección más amplia". Ya se ha dicho que ello se logra prefiriendo interpretaciones o normas con miras a obtener la mayor y mejor protección, pero sigue sin responderse, de manera concreta, cómo se verifica si una cierta interpretación o una determinada norma logran cumplir con ese mandato derivado del principio pro persona.

El jurista mexicano Miguel Carbonell considera que para elegir una norma o formular la interpretación de una norma, a partir del principio pro persona, es necesario atender a dos criterios: 1) si la norma o la interpretación de la norma "amplía el ámbito de los sujetos protegidos por el derecho", y 2) si la norma o la interpretación de la norma "amplía el perímetro material protegido por el derecho", identificando a dicho perímetro como el "ámbito de la realidad que el derecho regula". ${ }^{36}$ A pesar de que, efectivamente, esta propuesta se acerca a la concreción del mandato pro persona, lo cierto es que está limitada a reconocer su dimensión cuantitativa, dejando fuera del análisis la importancia y capacidad de la dimensión cualitativa de protección.

Lo que aquí se propone, a diferencia de una perspectiva que no distingue entre dimensiones, es que los criterios para determinar la concreción del mandato de "favorecer la protección más amplia" son necesariamente diversos en relación a la mayor o a la mejor protección. Así, la primera

36 Carbonell, Miguel, Los derechos humanos en México. Régimen jurídico y aplicación práctica, México, Flores, 2015, p. 39. 
de éstas siempre tendrá una base cuantitativa, y responde a dos preguntas básicas: 1) cuántos titulares son protegidos —elemento personal-, y 2) cuándo - elemento de temporalidad-; es decir, se refiere al número de sujetos y objetos protegidos, y al ámbito temporal de protección. En cambio, la segunda dimensión se corresponde con el criterio cualitativo de la mejor protección, respondiendo a otras dos preguntas: 1) qué se protege, y 2) cómo —elemento material—; en este ámbito se hace ahora hincapié, respectivamente, en los derechos cuya protección se pretende y en las modalidades de la protección, es decir, su grado de efectividad y su capacidad de expansión, incluyendo la materialidad de sujetos o poderes frente a los que se protege el derecho en juego.

Se podría resumir las vinculaciones entre dimensiones, elementos y criterios del principio pro persona, en el siguiente cuadro:

\begin{tabular}{|c|c|c|c|c|}
\hline Favorecimiento & Dimensiones & Elementos & Criterios & Objetos \\
\hline \multirow{2}{*}{$\begin{array}{l}\text { La mayor } \\
\text { protección }\end{array}$} & \multirow{2}{*}{$\begin{array}{l}\text { Dimensión } \\
\text { cuantitativa }\end{array}$} & $\begin{array}{l}\text { Elemento de } \\
\text { temporalidad }\end{array}$ & $\begin{array}{c}\text { ¿Cuándo se } \\
\text { protege? }\end{array}$ & $\begin{array}{c}\text { Ámbito } \\
\text { temporal de } \\
\text { protección }\end{array}$ \\
\hline & & $\begin{array}{c}\text { Elemento } \\
\text { personal }\end{array}$ & $\begin{array}{l}\text { ¿Quiénes son } \\
\text { protegidos? }\end{array}$ & $\begin{array}{l}\text { Sujetos y obje- } \\
\text { tos protegidos }\end{array}$ \\
\hline \multirow{2}{*}{$\begin{array}{l}\text { La mejor } \\
\text { protección }\end{array}$} & \multirow{2}{*}{$\begin{array}{l}\text { Dimensión } \\
\text { cualitativa }\end{array}$} & \multirow{2}{*}{$\begin{array}{l}\text { Elemento } \\
\text { material }\end{array}$} & $\begin{array}{l}\text { ¿Qué se } \\
\text { protege? }\end{array}$ & $\begin{array}{l}\text { Derechos } \\
\text { protegidos }\end{array}$ \\
\hline & & & $\begin{array}{l}\text { ¿Cómo se } \\
\text { protege? }\end{array}$ & $\begin{array}{l}\text { Modalidades } \\
\text { de protección }\end{array}$ \\
\hline
\end{tabular}

En fin, es necesario enfatizar lo anteriormente señalado, en el sentido de que sería contrario a la esencia misma del mandato de favorecimiento pretender aislar los elementos que lo componen, en detrimento de su interdependencia. Esta misma consideración se extiende a las dimensiones del principio pro persona y, por ende, a los criterios para su concreción y al objeto de cada uno de ellos, por lo que también respecto de todos estos conceptos se debe pregonar un vínculo de interdependencia e indivisibilidad. De este modo, sería inválido, por ejemplo, proponer una solución jurídica - normativa o interpretativa - a un caso concreto que tuviera como efecto o consecuencia el expandir el ámbito temporal de protección frente a una determinada vulneración de derechos, pero cuyo grado de efectividad fuere menor en comparación con alguna otra solución disponible. 


\section{UN ESQUEMA DE LA “FÓRMULA DEL MEJOR DERECHO”}

La complejización hasta ahora construida de la estructura del principio pro persona indicando no sólo su significado, sus directrices de preferencia y sus sentidos, sino además añadir sus elementos y dimensiones, alcanza para avanzar un tanto más en el camino hacia el develamiento de su misterio. Pero quedarse allí no es suficiente si lo que se busca es hacer efectivo este principio, que no deja de ser una herramienta. Por ello, ahora se intentará, a partir de lo anterior, un esquema concreto para su operacionalización.

El presupuesto para que este principio entre en función será la "existencia de un conflicto interpretativo o de aplicación de dos o más normas de derechos humanos". En particular cuando se está frente a una situación en que diversas normas jurídicas son aplicables, se debe tomar en cuenta que éstas pueden o no pertenecer a la misma fuente, pudiendo ser internas o internacionales. Si es esto último el caso, se tendrá que considerar las "remisiones normativas [como] canales de comunicación entre fuentes nacionales e internacionales de derechos humanos susceptibles de ser interpretadas, [así como] la interpretación que de ellos realicen sus intérpretes autorizados". ${ }^{37}$

En otras palabras, el presupuesto del principio pro persona es que exista una pluralidad de normas aplicables a un mismo caso, o bien basta con que exista una sola formulación normativa que, sin embargo, admita diversas interpretaciones jurídicamente válidas obtenidas mediante los métodos clásicos de interpretación. Aquí es importante destacar que, entonces, y sobre todo cuando actúa como directriz de preferencia interpretativa, el principio pro persona no remplaza a las distintas metodologías de interpretación jurídica ya desarrolladas en el campo jurídico — literalidad, finalidad, contextualidad, etcétera-, sino que se erige como un criterio metainterpretativo para preferir, de entre los significados válidamente producidos al emplear esos otros métodos, aquel que favorezca en mayor medida y de la mejor forma posible a las personas y a sus derechos.

En la misma tesitura, debe recalcarse la vinculación constitucional del principio pro persona con la interpretación conforme, y cuyo fundamento es el propio texto constitucional previamente trascrito. Esta relación

37 Caballero Ochoa, José Luis y García Huerta, Daniel Antonio, El principio pro persona en el..., cit. 
es sumamente importante, aunque no necesaria. Es fundamental en tanto que realizar un ejercicio de interpretación conforme exige que esté guiado siempre por el mandato de favorecimiento; pero, por otro lado, no es siempre necesaria, en el sentido de que el principio pro persona, como cláusula preferente, trasciende a la interpretación conforme: esto es así porque se trata de un mandato sustantivo que debe regir toda actuación de autoridad pública del Estado - especialmente las jurisdiccionales-, mientras que la interpretación conforme, como es entendida por la SCJN, entra en funcionamiento sólo cuando se ejerce un control de regularidad normativa. ${ }^{38}$

Luego, una vez satisfecho el presupuesto del ejercicio, lo primero que habrá que responderse es: a quién se debe favorecer. Resulta claro decir que a la(s) persona(s). Sin embargo, como fue mencionado anteriormente, Bobbio ya nos ha advertido que la norma jurídica es bilateral, en el sentido de que simultáneamente atribuye un derecho a uno de los sujetos e impone un deber al otro. ${ }^{39}$ Así, la mera afirmación de "persona" no llega realmente a decirnos cómo responder a la pregunta cuando ambos sujetos de la relación ostentan ese estatus.

De este modo, se hace necesario recurrir a un fundamento previo que contribuya a especificar a quién favorecer: a las personas o sujetos en situación de mayor vulnerabilidad en los distintos ejes que organizan el "patrón colonial de poder" y ámbitos en se despliega: el trabajo, el orden del sexo-género y sexualidad, la racialidad, la subjetividad, así como sus medios, instrumentos y productos materiales e inmateriales. ${ }^{40} \mathrm{La}$ "ley del más débil" es uno de los fundamentos que justifican la protección que proporcionan los derechos fundamentales, ${ }^{41} \mathrm{y}$ el principio pro persona busca reforzar esta protección, maximizando sus efectos o limitando sus restricciones, por lo que es válido sostener que el favorecimiento pretendido con este principio nunca es neutral, sino que se orienta hacia las personas que

38 SCJN, Varios 912/2010, Pleno, 14 de julio de 2011, ministra ponente: Margarita Beatriz Luna Ramos, ministro encargado del engrose: José Ramón Cossío Díaz, §33.

39 Bobbio, Norberto, Teoría general del..., cit., pp. 195 y ss.

40 Para un acercamiento, véase Quijano, Aníbal, "Colonialidad del poder y clasificación social”, Journal of World-Systems Research, Festschrift for Immanuel Wallerstein, I, vol. VI, núm. 2, verano-otoño de 2000, pp. 342-386; Lugones, María, "Colonialidad y género", Tabula Rasa, Bogotá, núm. 9, julio-diciembre de 2008, pp. 73-101.

41 Ferrajoli, Luigi, "Los fundamentos de los derechos fundamentales", en Cabo, Antonio de y Pisarello, Gerardo (eds.), Los fundamentos de los derechos fundamentales, Madrid, Trotta, 2009, pp. 317, 318, 362 y ss. 
han sido ubicadas en una posición inferiorizada en las distintas relaciones sociales de poder, o bien son subalternizadas dentro de estructuras y sistemas de dominación, explotación, exclusión, control o invisibilización.

Ahora bien, para identificar a los sujetos a quienes deba dirigirse el mandato de favorecimiento será necesaria, entre otras condiciones institucionales, una comprensión empática ${ }^{42}$ que permita percibir las circunstancias de cada persona, la construcción de su subjetividad a partir de mecanismos y dispositivos de racialización, generización, sexualización, su posición en el espacio social, ${ }^{43}$ así como las relaciones de poder que atraviesan el lugar que ocupa o su no-lugar. ${ }^{44}$ Esta identificación, aunque pudiere ser compleja, puede ser auxiliada por dos elementos, cada uno de los cuales actúa en dos tipos de relaciones diferentes: uno, cuando los dos sujetos de la relación jurídica son personas; el otro, cuando solamente uno de los sujetos es persona, en su acepción de ser humano, por ejemplo cuando se enfrenta al Estado o a un ente privado.

El primero de los elementos mencionados es el principio de no discriminación en sentido amplio, cuyo significado exige que toda situación, posición o relación de dominación - en forma de desigualdad, desventaja, exclusión, explotación, opresión, subalternización - sea visibilizada y reconocida para ser removida o trasformada lo más posible; así, el que uno de los sujetos se encuentre en alguna de estas situaciones de subordinación, será un indicio fuerte de que es el sujeto que merece la protección reforzada.

El segundo elemento se trata de una presunción de que las personas son los sujetos en situación de vulnerabilidad en aquellas relaciones en las que la contraparte no posee ese mismo estatus; esta presunción puede, ciertamente, ser destruida, pero para ello se traslada la carga argumentativa o probatoria a la contraparte. El fundamento de esta presunción se basa en el

\footnotetext{
42 Ferrajoli, Luigi, Derecho y razón. Teoría..., cit., pp. 158-165; Nussbaum, Martha, Justicia poética. La imaginación literaria y la vida pública, trad. de C. Gardini, Barcelona, Andrés Bello, 1997.

43 Véase Bourdieu, Pierre, Poder, derecho y clases sociales, trad. de Daniel Oliver Lalana y Andrés García Inda, Bilbao, Desclée de Brouwer, 2000, pp. 104-128.

44 En la lógica de la subalternidad el no-lugar es dado, puesto, impuesto al no-sujeto desde el "imperio de anulación del otro". Véase Spivak, Gayatri Chakravorty, "Can the Subaltern Speak?", en Nelson, C. y Grossberg, L. (eds.), Marxism and the Interpretation of Culture, Basingstoke, Macmillan Education, 1988, pp. 271-313; Adlbi Sibai, Sirin, La cárcel del feminismo. Hacia un pensamiento islámico decolonial, Madrid, Akal, 2016, pp. 33-72.
} 
valor de las personas, lo que "presupone una protección a priori de [sus] derechos e intereses". ${ }^{45}$

Ahora, una vez que se determina a quién se debe favorecer, y tomando en cuenta que existe una pluralidad de formulaciones normativas o de interpretaciones a ser aplicadas, es necesario identificar cuál es la favorable.

En este sentido, se deben tomar en consideración los tres elementos conformantes del mandato de favorecimiento: los elementos temporal, personal y material. Como es posible recordar, los dos primeros forman la dimensión cuantitativa del principio pro persona, mientras que el último es la base de su dimensión cualitativa. Ambas dimensiones guardan una interrelación estructural, así como los elementos del principio tienen un vínculo de interdependencia entre sí. Por ello mismo, no será válido argumentar que una determinada interpretación o formulación normativa son las favorables por potenciar alguno de los elementos mencionados, pero en detrimento de los restantes.

Entonces, identificar la solución jurídica que favorezca la mayor y mejor protección a las personas en todo tiempo consistirá, básicamente, en argumentar, respecto de cada una de las interpretaciones o normas aplicables, y responder, por ejemplo: con la norma $\mathrm{n}_{1}$, en comparación con la norma $\mathrm{n}_{2}$; o con la interpretación $\mathrm{i}_{1}$ o la interpretación $\mathrm{i}_{2}$, ambas de la disposición n:

- ¿Cuál es el ámbito temporal de protección?

- ¿A quiénes — sujetos y objetos - se protege?

- ¿Qué derechos se protegen?

- ¿Cómo se protege?

Es claro que no bastará con dar cualquier respuesta a las preguntas formuladas, sino que será necesario realizar ejercicios argumentativos que discutan y acrediten la mayor o menor capacidad de cada una de las opciones interpretativas o normativas disponibles para concretar el mandato constitucional de favorecimiento a las personas.

De manera esquemática, se puede presentar la propuesta en su conjunto de la siguiente manera:

1. Presupuesto: existencia de un conflicto interpretativo o normativo;

45 Caballero Ochoa, José Luis y García Huerta, Daniel Antonio, El principio pro persona..., cit., cursivas del original. 
2. ¿A quién se debe favorecer?

2.1. Identificación del sujeto en situación de subordinación:

2.1.1. Relaciones entre personas: principio de no discriminación;

2.2.1. Relaciones entre persona y no-persona: presunción a favor de la persona;

3. ¿Cuál es la solución favorable?

3.1. Dimensión cuantitativa: ¿se logra una mayor protección?

3.1.1. Elemento temporal: ¿cuál es el ámbito temporal de protección?;

3.1.2. Elemento personal: ¿a quiénes se protege?;

3.2. Dimensión cualitativa: ¿se obtiene una mejor protección?

3.2.1. Elemento material relativo a los derechos protegidos: ¿qué derechos se protegen?; y,

3.2.2. Elemento material relativo a las modalidades de la protección: ¿cómo se protege?

\section{APUNTES FINALES}

Para finalizar este trabajo, no se quiere perder la oportunidad de mostrar, aunque fuere brevemente, un ejercicio de argumentación utilizando del esquema aquí planteado a partir de una comprensión de la compleja estructura del principio pro persona. La pregunta fundamental escogida no es hipotética, sino que derivó en su momento de la línea jurisprudencial que la Primera Sala de la SCJN ha venido construyendo en relación con el matrimonio entre personas del mismo sexo en distintas entidades federativas de México, y que ha llegado hasta ahora en la consolidación de la tesis jurisprudencial 43/2015. ${ }^{46}$ Se considera que este ejemplo puede mostrar con un buen grado de claridad la forma de hacer operativo este principio frente a preguntas concretas relativas a la protección de derechos de sujetos o grupos en situaciones de vulnerabilidad.

46 SCJN, tesis 1a./J. 43/2015, de rubro: "MATRIMONIO. La ley de cualquier entidad federativa que, por un lado, considere que la finalidad de aquél es la procreación y/o que lo defina como el que se celebra entre un hombre y una mujer, es inconstitucional", Semanario Judicial de la Federación y su Gaceta, Décima Época, t. I, junio de 2015, p. 536, registro IUS: 2009407. 
1. Dada la TJ-43/2015 de la Primera Sala, ¿quedan o no de alguna manera vinculadas las autoridades administrativas locales cuyas normas civiles excluyen implícita o explícitamente del matrimonio a las parejas homosexuales?

Una vez que los criterios plasmados en la TJ-43/2015 conforman jurisprudencia, en términos de los artículos 99 constitucional y 217 de la Ley de Amparo, se vuelven obligatorios para todos los órganos judiciales del país, sin importar su nivel o su fuero, pero no se menciona explícitamente ninguna otra autoridad legislativa o administrativa. Es la literalidad -o el silencio- del artículo 217 de la Ley de Amparo la que excluye la posibilidad de sustentar que las autoridades registrales invoquen en su actuación la TJ-43/2015-PS.

Por otro lado, el artículo 1o. constitucional impone a todas las autoridades la obligación de promover, respetar, proteger y garantizar los derechos humanos a partir de los principios de universalidad, interdependencia, indivisibilidad y progresividad; en tal sentido, al Estado en su conjunto le corresponde los deberes de prevenir, investigar, sancionar y reparar las violaciones a los derechos de las personas; finalmente, se explicita la prohibición de toda forma de discriminación por cualquier razón que atente contra la dignidad humana y tenga por objeto anular o menoscabar los derechos mismos; es decir, dichas obligaciones, deberes y prohibiciones no hacen distingo entre autoridades, sin importar el poder público al que pertenezcan o su función formal o material. De conformidad con esta construcción, una vez determinada la inconstitucionalidad de las disposiciones civiles que excluyen del matrimonio a las parejas homosexuales, podría vincularse a las autoridades administrativas a no aplicarlas en su literalidad.

Como es posible notar, la segunda opción, la referida a vincular a las autoridades administrativas de alguna forma con la determinación de inconstitucionalidad realizada por la Primera Sala de la SCJN, pretende extender el rango de efectividad del derecho a la no discriminación de modo que para quedar bajo su protección no se tenga que recurrir necesariamente a un proceso judicial, sino que pueda serlo incluso en sede administrativa, al momento en que se decide si se autoriza o no la celebración de un matrimonio por dos personas del mismo sexo.

Es el principio de no discriminación en sentido amplio el que permite reconocer la construcción estructuralmente excluyente de los ordenamien- 
tos civiles respecto de las personas homosexuales como no-sujetos, invisibilizadas ${ }^{47}$ en su existencia legítima y pública del discurso normativo y simbólico $^{48}$ de una institución importante, como lo es el matrimonio, en una sociedad liberal heteropatriarcal. Pero también logra introducir una mirada crítica desde la clase, poniendo de manifiesto que las posibilidades reales - económicamente hablando - de que una pareja pueda no solamente iniciar su trámite de celebración de matrimonio, sino además contratar y pagar asesoría jurídica para llevar a término un juicio de amparo, o bien hacerlo por sí - lo cual a su vez implica necesariamente un cierto bagaje educativo especializado que igualmente está cruzado por la clase- - se reducen dramáticamente.

Así las cosas, la favorabilidad debe dirigirse hacia las personas homosexuales y lesbianas, ${ }^{49} \mathrm{y}$ las familias que forman, en tanto prevalece la presunción de favorabilidad en su relación con las autoridades y órganos del Estado. Ello salvo que el Estado argumente y demuestre que, en concreto, no exista una situación o posición de vulnerabilidad.

Ahora bien, se debe responder: ¿pueden las autoridades de los registros civiles en las entidades federativas autorizar y celebrar matrimonios conformados por personas del mismo sexo, a pesar de lo dispuesto en las normas civiles locales que las excluyen, invocando la determinación de su inconstitucionalidad realizada por la SCJN en la TJ-43/2015-PS?

La primera solución, fundamentada en la literalidad de la Ley de Amparo sostiene que, dado que la jurisprudencia no obliga a las autoridades administrativas, éstas pueden negarse a autorizar estos matrimonios, aunque queda a salvo el derecho a recurrir a la protección judicial de un juzgado federal. La segunda solución, basada fundamentalmente en el artículo 1o. de la CPEUM, sostiene que a estas autoridades compete la obligación

47 Véase Caballero Ochoa, José Luis y García Huerta, Daniel Antonio, "El enigma, el candil y el vigía decidido. Los claroscuros del matrimonio igualitario en la jurisprudencia mexicana", en Alterio, Ana Micaela y Niembro Ortega, Ricardo (coords.), La Suprema Corte y el matrimonio igualitario en México, México, UNAM, Instituto de Investigaciones Jurídicas, 2017, pp. 203-231.

48 Bourdieu, Pierre, La dominación masculina, trad. de Joaquín Jordá, 9a. ed., Barcelona, Anagrama, 2015, pp. 143-149.

49 Aquí entiendo el lesbianismo y la homosexualidad no como categorías identitarias esencialistas de la sexualidad, sino como construcciones sociales y posicionamientos políticos en un régimen heteronormativo. Véase Curiel, Ochy, La nación heterosexual. Análisis del discurso jurídico y el régimen heterosexual desde la antropología de la dominación, Bogotá, Brecha Lésbica-En la Frontera, 2013, p. 28. 
constitucional de interpretar las normas civiles que están llamadas a aplicar de manera que sean conformes con los derechos a la igualdad y a la no discriminación, por lo que ya no les es jurídicamente válido negarse a celebrar matrimonios cuando dos personas del mismo sexo lo soliciten por ese solo hecho.

Es posible argumentar que la segunda solución, a diferencia de la primera de ellas, posibilita una mayor protección, en razón de que más personas son las que se presentan ante el Registro Civil a solicitar contraer matrimonio, que las que tienen posibilidad real de iniciar un proceso judicial en contra de la negativa de la autoridad registral de dar la autorización correspondiente. Igualmente, la tutela es temporalmente mayor, puesto que desde el momento mismo que las personas se presentan a solicitar matrimonio se hacen efectivas las obligaciones de respetar y garantizar sus derechos, y no tienen que esperar hasta que se dicte una sentencia definitiva por autoridad judicial que les otorgue el amparo correspondiente.

Del mismo modo, la segunda opción representa una mejor concepción del derecho a la igualdad y a la no discriminación, el cual sería oponible y, por tanto, efectivo ante autoridades administrativas, y no solamente ante autoridades judiciales. La consecuencia de la primera solución, en contrapartida, es que quedaría al arbitrio de las autoridades administrativas el cumplimiento de sus obligaciones constitucionales de respeto y garantía de los derechos de las personas, así como sus deberes de prevenir y reparar las violaciones a los mismos, desconociendo con ello su obligación de interpretar las normas conforme los principios y derechos constitucionales.

Entendido de esta manera, se puede argumentar que se obtiene una $m a-$ yor y mejor protección de las personas si se considera que las autoridades administrativas deben fundar sus actos en la determinación de inconstitucionalidad realizada por la SCJN de aquellas normas civiles que excluyan la posibilidad de que personas del mismo sexo accedan al matrimonio.

Así, al interpretar esas disposiciones normativas, de forma que se garanticen los derechos a la igualdad y a la no discriminación de estas personas, se cumplen los mandatos constitucionales contenidos en el artículo 1o. constitucional, pero sin trasgredir su esfera de competencia, puesto que no se trata de que declaren la inconstitucionalidad de las normas - que ya lo hizo la $\mathrm{SCJN}$ - , tampoco de que las modifiquen legislativamente - lo cual compete exclusivamente al congreso local de que se trate-, pero sí que, previo a su aplicación —a la cual están vinculadas por el principio 
de legalidad-, les asignen el significado que más y mejor favorezcan a las personas de sexualidades e identidades no normativas y a sus familias.

2. Con lo construido hasta ahora se puede sostener que la estructura del principio pro persona es polifacética y compleja, puesto que concurren en él diversos sentidos, directrices, dimensiones, elementos, criterios y objetos, aunque siempre en torno a un único significado: favorecer la protección de las personas. Si se quisieren organizar gráficamente las facetas estructurales del principio pro persona, se podría pensar en lo siguiente:

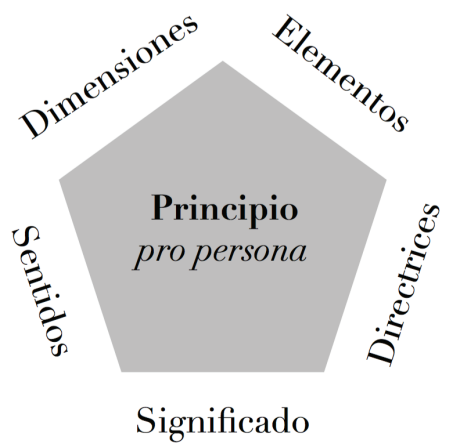

De hecho, esta figura con cinco puntos de referencia permite entender gráficamente lo hasta ahora desarrollado: el significado del principio mismo, que es el favorecimiento de las personas, se encuentra en la base de cualquier ejercicio que se pretenda formular en torno a aquél; luego, tanto los sentidos — positivo o negativo - como las directrices de preferencia - normativa o interpretativa - fijan los parámetros dentro de los cuales se realizará el ejercicio, determinando si lo que se busca en concreto es proponer una maximización de un derecho o la limitación a su restricción, así como si ello se hace a partir de diversas interpretaciones de una misma formulación normativa, o de diferentes normas jurídicamente aplicables; por último, tanto las dimensiones — cuantitativa y cualitativa-, como los elementos del principio - temporal, personal y material — confluyen para formar el punto de cierre del radio de aplicación del principio, contribuyendo a identificar cuál es la solución jurídica - interpretativa o normativa- que favorece la mayor y mejor protección de las personas y de sus derechos fundamentales. 
La elaboración de lineamientos a partir de la estructura del principio pro persona es una propuesta cuya utilidad ha intentado ser mostrada en este último apartado, con el ánimo de contribuir a debatir, discutir y argumentar de manera más adecuada las posibles soluciones a los conflictos normativos o interpretativos que se presentan en materia de derechos humanos, dejando claro en cualquier caso que el objetivo final es reducir los espacios de arbitrariedad judicial, ensanchados por nociones confusas que terminan justificando cualquier tipo de decisión, al no haber pautas que evalúen su plausibilidad o su coherencia con el significado del mandato de lo más favorable.

Por ello, la idea es que la invocación del principio pro persona para fundamentar la solución favorable exige diversos ejercicios de interpretación y de argumentación que se harán caso por caso, siempre a partir de una comprensión empática y de una orientación claramente en favor de los sujetos en situaciones, posiciones o relaciones de subordinación, desterrándose la idea de que lo más favorable es evidente y reconocible intuitivamente.

Se considera que la propuesta aquí sustentada, o al menos las consideraciones que la conforman, contribuyen a la elaboración más puntual de un esquema con mayor capacidad prestacional para facilitar la operacionalización del principio pro persona por parte de los órganos encargados de la función judicial, principalmente, pero también puede orientar la actividad que en la materia corresponde a las demás autoridades públicas, las cuales están igualmente obligadas por el mandato constitucional de favorecer a las personas en cualquier tiempo la mayor y mejor protección.

\section{BiBLIOGRAFÍA}

Adlbi Sibai, Sirin, La cárcel del feminismo. Hacia un pensamiento islámico decolonial, Madrid, Akal, 2016.

Alexy, Robert, Teoría de los derechos fundamentales, trad. de Carlos Bernal Pulido, Madrid, Centro de Estudios Políticos y Constitucionales, 1986.

Boвbio, Norberto, Teoría general del derecho, trad. de J. Guerrero, Bogotá, Temis, 2012. 
Bourdieu, Pierre, La dominación masculina, trad. de Joaquín Jordá, 9a. ed., 2015, Barcelona, Anagrama, 2000.

Bourdieu, Pierre, Poder, derecho y clases sociales, trad. de Daniel Oliver Lalana y Andrés García Inda, Bilbao, Desclée de Brouwer, 2000.

CABallero OchoA, José Luis, "La cláusula de interpretación conforme y el principio pro persona (artículo primero, segundo párrafo, de la Constitución)", en Carbonell, Miguel y Salazar Ugarte, Pedro (coords.), La reforma constitucional de derechos humanos: un nuevo paradigma, México, Porrúa-UNAM, Instituto de Investigaciones Jurídicas, 2012.

Caballero Ochoa, José Luis y García Huerta, Daniel Antonio, "El enigma, el candil y el vigía decidido. Los claroscuros del matrimonio igualitario en la jurisprudencia mexicana", en Alterio, Ana Micaela y Niembro OrtegA, Ricardo (coords.), La Suprema Corte y el matrimonio igualitario en México, México, UNAM, Instituto de Investigaciones Jurídicas, 2017.

Caballero Ochoa, José Luis y García Huerta, Daniel Antonio, “El principio pro persona en el marco del sistema de interpretación sobre los derechos humanos en México", en Ferrer MAC-Gregor, Eduardo (coord.), Derecho procesal constitucional transnacional. Interacción entre el derecho nacional y el internacional, México, Porrúa-Instituto Mexicano de Derecho Procesal Constitucional, 2016.

Carbonell, Miguel, Los derechos humanos en México. Régimen jurídico y aplicación práctica, México, Flores, 2015.

CARbonell, Miguel, "El neoconstitucionalismo: significado y niveles de análisis", en CARbonell, Miguel y García Jaramillo, Leonardo (eds.), El canon neoconstitucional, Madrid, Trotta, 2010.

Carbonell, Miguel, Los derechos fundamentales en México, México, CNDH-UNAM, 2004.

CAstilla, Karlos, "El principio pro persona en la administración de justicia", Cuestiones Constitucionales, núm. 20, enero-junio de 2009.

CuRIEL, Ochy, La nación heterosexual. Análisis del discurso jurídico y el régimen heterosexual desde la antropología de la dominación, Bogotá, Brecha Lésbica-En la Frontera, 2013.

Dworkin, Ronald, Los derechos en serio, trad. de M. Guastavino, España, Ariel, 1977. 
FerRajoli, Luigi, La democracia a través de los derechos. El constitucionalismo garantista como modelo teórico y como proyecto político, trad. de Perfecto Andrés Ibáñez, Madrid, Trotta, 2014.

Ferrajoli, Luigi, "Constitucionalismo principialista y constitucionalismo garantista, un debate sobre el constitucionalismo. Monográfico", Doxa, núm. 34, trad. de N. Guzmán, Madrid, Marcial Pons-Doxa, 2012.

Ferrajoli, Luigi, "Los fundamentos de los derechos fundamentales", en Cabo, Antonio de y Pisarello, Gerardo (eds.), Los fundamentos de los derechos fundamentales, Madrid, Trotta, 2009.

Ferrajoli, Luigi, "Pasado y futuro del Estado de derecho", en CARBoNELL, Miguel (ed.), Neoconstitucionalismo(s), trad. de P. Allegue, Madrid, Trotta, 2009.

FerRAJoli, Luigi, Garantismo. Una discusión sobre derecho y democracia, trad. de Andrea Greppi, Madrid, Trotta, 2006.

Ferrajoli, Luigi, Derechos y garantías. La ley del más débil, trad. de Perfecto Andrés Ibáñez y Andrea Greppi, Madrid, Trotta, 1999.

Ferrajoli, Luigi, Derecho y razón. Teoría del garantismo penal, trad. de Perfecto Andrés et al., Madrid, Trotta, 1995.

Fioravanti, Maurizio, Los derechos fundamentales. Apuntes de historia de las Constituciones, trad. de M. Martínez Neira, Madrid, Trotta, 1996.

GuASTINI, Riccardo, Interpretar y argumentar, trad. de Silvina Álvarez Medina, Madrid, Centro de Estudios Políticos y Constitucionales, 2014.

Guastini, Riccardo, "Para una taxonomía de las controversias entre juristas", en LuQue Sánchez, Pau y RatTi, Giovanni Battista (eds.), Acordes y desacuerdos. Cómo y por qué los juristas discrepan, Madrid, 2012.

Henderson, Humberto, "Los tratados internacionales de derechos humanos en el orden interno: la importancia del principio pro homine", Revista del Instituto Interamericano de Derechos Humanos, núm. 39, enero-junio de 2004.

López Sánchez, Rogelio, Interpretación constitucional de los derechos fundamentales. Nuevos paradigmas hermenéuticos y argumentativos, México, Porrúa, 2013.

Lugones, María, “Colonialidad y género”, Tabula Rasa, núm. 9, Bogotá, julio-diciembre de 2008. 
Medellín Urquiaga, Ximena, "Principio pro persona", Metodología para la enseñanza de la reforma constitucional en materia de derechos humanos, México, Suprema Corte de Justicia de la Nación-Oficina en México del Alto Comisionado de las Naciones Unidas para los Derechos Humanos-Comisión de Derechos Humanos del Distrito Federal, 2013.

Nash RoJAs, Claudio, "El principio pro persona en la jurisprudencia de la Corte Interamericana de Derechos Humanos", en Nogueira Alcalá, Humberto (coord.), Diálogo judicial multinivel y principios interpretativos favor persona y de proporcionalidad, Santiago de Chile, Librotecnia-Centro de Estudios Constitucionales de Chile, 2013.

Nussbaum, Martha, Justicia poética. La imaginación literaria y la vida pública, trad. de C. Gardini, Barcelona, Andrés Bello, 1997.

OrTega García, Ramón, El modelo constitucional de derechos humanos en México. Estudios sobre constitucionalización del derecho, México, Tirant lo Blanch México, 2015.

PINTo, Mónica, "El principio pro homine. Criterios de hermenéutica y pautas para la regulación de los derechos humanos", en ABREGÚ, M. y Courtis, Christian (comps.), La aplicación de los tratados sobre derechos humanos por los tribunales locales, Buenos Aires, Editores del Puerto, 1997.

Piza Rocafort, Rodolfo, y Trejos, Gerardo, Derecho internacional de los derechos humanos: la Convención Americana, San José, Juricentro, 1989.

Prieto Sanchís, Luis, "Supremacía, rigidez y garantía de la Constitución”, en Bernal Pulido, Carlos y Herber, Joel (eds.), Control constitucional y activismo judicial, Perú, Ara Editores, 2012.

QuiJano, Aníbal, "Colonialidad del poder y clasificación social", Journal of World-Systems Research, Festschrift for Immanuel Wallerstein, I, vol. VI, núm. 2, verano-otoño de 2000.

SAGÜÉs, Néstor Pedro, "La interpretación de los derechos humanos en las jurisdicciones nacional e internacional", Anales de la Academia Nacional de Derecho y Ciencias Sociales de Buenos Aires, Segunda Época, año XLIII, núm. 36, 1998.

SEPúlveda IguínIz, Ricardo, "El reconocimiento de los derechos humanos y la supremacía de la Constitución”, en Rosario Rodríguez, Mar- 
cos del (ed.), Supremacía constitucional, México, Porrúa-Universidad Panamericana, 2009.

SPIVAK, Gayatri Chakravorty, "Can the Subaltern Speak?”, en Nelson, C. y GrossberG, L. (eds.), Marxism and the Interpretation of Culture, Basingstoke, Macmillan Education, 1988.

WINch, Peter, The Idea of a Social Science and its Relation to Philosophy, 2a. ed., 1990, Londres, Routledge, 1958.

Zagrebelsky, Gustavo, El derecho dúctil. Ley, derechos, justicia, trad. de Marina Gascón, Madrid, Trotta, 2011.

Fecha de recepción: 9 de enero de 2017.

Fecha de dictamen: 24 de mayo de 2017. 